GHANA JOURNAL OF DEPARTMENT OF HEALTH, PHYSICAL EDUCATION AND RECREATION, SPORTS AND DANCE (GJOHPERSD)

Volume 7 \& 8, Year 2014 \& 2015

A JOURNAL OF THE DEPARTMENT OF HEALTH, PHYSICAL EDUCATION AND RECREATION (HPER)

UNIVERSITY OF CAPE COAST

GHANA, WEST AFRICA 


\title{
EVALUATION OF MUSCULOSKELETAL FITNESS AND ITS RELATIONSHIP TO QUALITY OF LIFE OF UNIVERSITY ACADEMIC STAFF IN NIGERIA
}

\author{
Michael, G. \& Oladipo, I.O. (Ph.D) \\ Department of Human Kinetics and Health Education \\ University of Ibadan, Ibadan, Nigeria
}

\begin{abstract}
This study was carried out to evaluate the musculoskeletal fitness and its relationship to quality of life of university academic staff in Nigeria. Teaching staff served as the target population. Forty academic staff volunteered and registered for the study in University of Ibadan but the total number of participants that completed the study was thirty six (36). Quasi-experimental research design was used for the study. The data collected were subjected to statistical analysis using descriptive statistics of mean and standard deviation and inferential statistics of pairwise t-test and Pearson Product Moment Correlation to test the hypotheses at 0.05 level of significance. The mean score of physical health quality of life of the participants showed that the participants rated themselves as having good quality of life. However, the t-test values show that the participants' do not possess adequate musculoskeletal fitness required to carry out their activities of daily living (ADLs). The correlational $r$ values of musculoskeletal components are .074, .029, .126 and .059 which are lower than the critical value of .4683. The implication of this is that the assumption made that the participants possess good quality of life is not supported by the results of their musculoskeletal tests. The findings indicated that no significant relationship exist between
\end{abstract}


Michael, G. \& Oladipo, I.O. (Ph.D) participants' musculoskeletal status and their quality of life. Based on the findings, it was concluded that exercise programme should be put forth to enhance musculoskeletal fitness and improve the quality of life of academic staff in the Universities.

Keywords: Musculoskeletal-fitness, quality of life, academic staff

39 A Journal of the Department of Health, Physical Education and Recreation 
Evaluation of Musculoskeletal Fitness and its Relationship to Quality of Life of University Academic Staff in Nigeria

\section{Introduction}

Bones, cartilages, muscles, joints, tendons and ligaments in a person's body compose what is known as the musculoskeletal system. The bones provide the body with a framework, giving it shape and support; they also serve as protection for internal organs such as the lungs and liver. Muscles are fibers that help to make deliberate movement of a body part or involuntary movement within an internal organ possible. Some people view this system as two separate systems that work very closely together, with one being the muscular system and the other being the skeletal system.

High levels of musculoskeletal fitness can enhance one's capacity to meet the demands of everyday life thereby allowing an individual to maintain functional independence for a greater period of time. Musculoskeletal fitness promotes and maintains overall health and athletic performance. It is associated with numerous health benefits, including a reduced risk of coronary heart disease, osteoporosis, glucose intolerance and musculoskeletal injuries. An increase in musculoskeletal fitness, in terms of athletic performance, leads to improved agility and enhanced athletic ability. Musculoskeletal fitness is part of everyday life; walking, lifting things, attending to daily tasks and playing sports are examples of how musculoskeletal fitness is needed to carry out activities of daily living without undue fatigue.

According to Kell, Bell \& Quinney (2001) a healthy musculoskeletal system is also associated with improved ability to complete activities of daily living and is directly related to quality of life. Ultimately, high levels of musculoskeletal fitness are associated with positive health status, whereas lower levels of musculoskeletal fitness are associated with lower health status (Warburton, Gledhill \& Quinney (2001). The longer a person is able to maintain musculoskeletal fitness, the longer the person will remain an independent person in the society to old age.

Quality of life (QOL), in general is the perceived quality of an individual's daily life, that is, an assessment of their well-being or lack thereof. These include all emotional, social and physical aspects of the individual's life. In health care, health-related 
quality of life (HRQOL) is an assessment of how the individual's well-being may be affected over time by a disease, disability or disorder.

Quality of life is a broad multidimensional concept that usually includes subjective evaluations of both positive and negative aspects of life. Quality of life encompasses the physiological, psychological, emotional and spiritual well-being of an individual (Warburton, Gledhill, \& Quinney, 2001). An assessment of the effect of high levels of musculoskeletal fitness on indicators of QOL is important because of the impact of QOL in the prevention of chronic disease and delivery of daily tasks without undue fatigue (Hennessy, Moriarty, Zack, Scherr \& Brackbill, 1994). Quality of life on the individual level include physical and mental health perceptions and their correlates including health risks and conditions, functional status, social support, and economic status. However this study addressed just the physiological and functional status of university academic staff of University of Ibadan, Ibadan, Nigeria.

Functional status refers to the ability to carry out the activities of daily living (ADLs). Enstrud et al., (1994) are of the opinion that as functional capacity decreases, disability and the need for institutionalization or hospitalization increases, along with the rate of premature mortality. High levels of musculoskeletal fitness enhance one's capacity to meet the demands of everyday life thereby allowing an individual to maintain functional independence for a greater period of time. With the aging population, improved functional status will increasingly become a greater concern for the university academic staff especially with academic staff retirement age in Nigeria that has been fixed at seventy years. Many elderly persons currently live near or below the functional threshold of musculoskeletal fitness for daily living.

Warburton, et al (2001) opined that musculoskeletal system has four elements; which are muscular strength, endurance, power and flexibility. Muscular strength is the maximal one-effort force that can be exerted against a resistance. Certain level of strength is needed, without which it would be impossible to carry out many of 
Evaluation of Musculoskeletal Fitness and its Relationship to Quality of Life of University Academic Staff in Nigeria

the simple everyday tasks such as lifting objects or even maintaining an upright posture. Strength training has been shown to offset the loss in muscle strength and mass (sarcopenia) associated with aging, which may increase the ability to perform ADLs and improve bone health (Warburton, et al., 2001) Also, high levels of muscular strength allow an individual to engage in more recreational activities, which will help to off-set sarcopenia and disuse-related diseases. Therefore, achieving high levels of muscular strength is an effective means of maintaining functional status.

Muscular endurance is the ability of the muscles to apply a sub-maximal force repeatedly or to sustain a muscular contraction for a certain period of time. From a QOL point of view, it is important for an individual to carry objects and perform repeated contractions for extended periods of time without fatiguing. According to Canadian Society for Exercise Physiology (1996) many tasks of everyday living require good muscular endurance. Salem, Wang, Young, Marion and Greendale (2000) also reported that muscular endurance was directly associated with several functional outcomes.

Muscular power is known as the explosiveness of a muscle. It involves a combination of muscular strength and speed. Although, muscular power is thought to be more important for optimal sport performance than personal health status, many ADLs require the capacity to apply a force quickly, thus, muscular power is associated with functional capacity and the potential to perform ADLs.

Flexibility according to Kell, et al., 2001) has two components, dynamic and static, where dynamic flexibility is the opposition or resistance of a joint to motion (the forces opposing movement rather than the range of movement itself). Static flexibility is the range of motion permissible about a joint. Flexibility is an indicator of health status; an improvement in flexibility is thought to result in a decreased incidence of injuries and an increased performance during physical activities. A reduced flexibility has been associated with decreased functional abilities, 
Michael, G. \& Oladipo, I.O. (Ph.D) including a lowered walking velocity and increased difficulty climbing stairs and getting up from a chair (Escalante, Lichtenstein, Dhanda, Cornell \& Hazuda, 1999). Reduced flexibility has also been associated with a reduction in health status, including increased self-reported pain and a reduction in perceived health, physical function, social function, mental health, and overall QOL (Payne, Gledhill, Katzarmzyk, Jamnik \& Ferguson, 2000).

According to Erick and Smith (2013) musculoskeletal diseases represents a common occupational problem in the teaching profession in Australia and teachers represent an occupational group among which there appears to be a high prevalence of MSD. The work of a teacher especially in the university, does not only involve teaching students but also preparing lessons, assessing students' work, research, community service and also being involved in extracurricular activities such as sports, field work, trips and project supervision. Teachers are essential for the effective functioning of the educational system and for improving the quality of learning processes.

The work of teachers often involves significant use of a 'head down' posture, such as frequent reading, marking of assignments, and prolonged sitting or standing; all these have significant effects on their musculoskeletal system. This study therefore aimed at looking into individual, physical and physiological variables and how it affects the quality of life of university academic staff.

\section{Research Hypotheses}

The following hypotheses were tested in this study:

1. University Academic staff in University of Ibadan, Nigeria will not significantly possess adequate musculoskeletal fitness (muscular strength, muscular endurance, power, and flexibility).

2. There will be no significant relationship between musculoskeletal fitness and physical health quality of life of academic staff in University of Ibadan. 
Evaluation of Musculoskeletal Fitness and its Relationship to Quality of Life of University Academic Staff in Nigeria

\section{Research design}

The design for this study was quasi-experimental research design. The design enabled the establishment of cause-effect relationships between musculoskeletal fitness and quality of life of university academic staff. This design was chosen because the researcher has no control over the variables of interest and therefore cannot manipulate them.

\section{Sample and Sampling Techniques}

Forty academic staff volunteered for the study, however only thirty-six completed it. University of Ibadan was purposively selected being the first university in Nigeria with large population of academic staff. The University has seventeen (17) faculties and five were randomly selected. Through the use of banners and social media, forty volunteers were recruited. Those that took part in the assessment were mainly male academic staff.

\section{Instruments and Data collection Procedure}

The following research tests and instruments were used in the course of this study:

Grip Strength Dynamometer T.K.K. 5401 Grip - D, manufactured by Takie Scientific Instruments Co. LTD, Japan and calibrated from $0-100 \mathrm{~kg}$ was used for arm strength test. Hana portable weight measuring scale (RA 9012) made in England was used to measure the total body weight of the participants in kilogram $(\mathrm{kg})$. Stadiometer was used to measure participants' height to the nearest 0.5 centimeter. Static Vertical Jump was used to measure participants' leg power. A calibrated sit-and-reach box was used for measuring trunk and hamstring flexibility of the participants. The track star jewels digit stopwatch made in Switzerland was used in timing the participants. A 50 meter length measuring tape was used for taking measurements where necessary. Sit-up test was used to test for abdominal strength. Sit-and-reach test was used for flexibility test. While the World Health Organisation Quality of Life Questionnaire (WHOQoL) (2012) was used to elicit information about the quality of life of participants as related to their daily living. 


\section{Test location}

All the tests and measurements were done at the Human Performance Laboratory of the Department of Human Kinetics and Health Education, University of Ibadan, Ibadan, Nigeria.

\section{Results and Discussion}

The participants demographic data revealed that although the retirement age of University academic staff in Nigeria has recently elongated to 70 years only $22.2 \%$ of the participants have their age close to retirement. However none is below age 40 .

The three age ranges of the participants indicated that those between 40 - 49years were $12(33.3 \%)$, for $50-59$ years they were $16(44.4 \%)$ and for $60-69$ years they were $8(22.2 \%)$.

The length of employment of the participants falls within range 5-10years $12(33.3 \%), 11-15$ years were $12(33.3 \%), 16$ 20years were $6(16.7 \%), 21-25$ years $2(12.5 \%), 26-30$ years 2 $(12.5 \%)$ and $30 y e a r s$ and above has $2(12.5 \%)$.

Table1: Mean and standard deviation values for musculoskeletal components $n=36$

\begin{tabular}{llll}
\hline Variables & & Mean & $\begin{array}{l}\text { Standard } \\
\text { deviation }\end{array}$ \\
\hline $\begin{array}{l}\text { Combined arm } \\
(\mathrm{kg})\end{array}$ & strength & 58.58 & 20.89 \\
$\begin{array}{l}\text { Abdominal endurance (sit- } \\
\text { up) }\end{array}$ & 17.33 & 6.83 \\
$\begin{array}{l}\text { Leg power }(\mathrm{cm}) \\
\text { Flexibility }(\mathrm{cm})\end{array}$ & 27.94 & 5.99 \\
\hline
\end{tabular}

Table 1 shows the mean and standard deviation values for musculoskeletal components. The value for combined arm strength for all the participants was $58.58 \pm 20.89$, while $17.33 \pm 6.83$ was the value for abdominal endurance. The values for leg power and flexibility were $27.94 \pm 5.99$ and $1.34 \pm 10.20$ respectively.

\section{Hypotheses Testing}


Evaluation of Musculoskeletal Fitness and its Relationship to Quality of Life of University Academic Staff in Nigeria

Ho 1: Male Academic staff of Nigeria Universities will not significantly possess adequate musculoskeletal fitness (muscular strength, endurance, power and flexibility) required for their activities of daily living.

Table 2: Comparative analysis of participants musculoskeletal fitness with standardized norm

\begin{tabular}{lccccccc}
\hline Variables & N & Mean & $\begin{array}{c}\text { Std. } \\
\text { Dev. }\end{array}$ & $\begin{array}{l}\text { Crit- } \\
\text { t }\end{array}$ & Cal-t. & DF & P \\
\hline $\begin{array}{l}\text { Participants' } \\
\text { Arm strength }\end{array}$ & 36 & 60.97 & 21.3 & & & & \\
$\begin{array}{l}\text { Arm strength } \\
\text { norm }\end{array}$ & 89.33 & 2.2 & & & & \\
$\begin{array}{l}\text { Abdominal } \\
\text { Endurance }\end{array}$ & 36 & 18.0 & 6.66 & & & & \\
$\begin{array}{l}\text { Abdominal } \\
\text { Endurance }\end{array}$ & & 34.83 & 4.52 & & 10.48 & & \\
$\begin{array}{l}\text { Norm } \\
\text { Leg power }\end{array}$ & 36 & 28.94 & 4.65 & & & & \\
$\begin{array}{l}\text { Leg power } \\
\text { Norm }\end{array}$ & 32.83 & 1.51 & & & & \\
Leg power & 16 & 1.26 & 10.25 & & & & \\
$\begin{array}{l}\text { Standardized } \\
\text { Leg power }\end{array}$ & 16 & 21.33 & 1.28 & & & & \\
\hline
\end{tabular}

When the mean value for the participants' arm strength of $60.97 \pm 21.3$ was compared with the expected norm value of 89.33 \pm 2.2 it shows that there is a significant difference between the combined arm strength of male participants with the standardized norm. The cal. $t$ value of -5.59 is greater than the Critical value of 2.0 at $\mathrm{df}$ of 17. Likewise the calculated P of .000 is less than 0.05 level of significance. This result therefore, shows that the 
participants does not possess adequate arm strength required for their activities of daily living.

Table 2 still shows that there is a significant difference between the participants' abdominal endurance and standardized abdominal endurance. The cal. $t$ value of -10.48 is greater than the critical-t value of 2.0 at $\mathrm{df}$ of 17 . In the same manner the cal. $p$ of 0.000 is less than 0.05 level of significance. This result therefore, shows that the participants possess inadequate abdominal endurance required for their day-to-day activities.

Table 2 further the mean value for the male participants' leg power to be $28.94 \pm 4.65$ while the expected norm value is $32.83 \pm 1.51$, this shows that there is a significant difference between the leg power of male participants with the standardized norm. The cal. $t$ value of -3.65 is greater than the Critical value of 2.0 at $\mathrm{df}$ of 17 . Likewise the calculated $\mathrm{p}$ of 0.002 is less than 0.05 level of significance. This result therefore, shows that the participants does not possess adequate leg power required for their activities of daily living.

The mean and standard deviation values for the male participants' flexibility to be $1.26 \pm 10.25$ and the norm value of $21.33 \pm 1.28$ which shows that there is a significant difference between the flexibility of male participants with the standardized norm. The cal.t value of -7.86 which is higher than the critical $t$ value of 2.0, further confirms the significant difference. The cal. $p$ value of 0.000 is less than 0.05 level of significance. This result shows that male academic staff do not possesses adequate flexibility required for their activities of daily living.

Ho 2: There will be no significant relationship between musculoskeletal fitness and quality of life of academic staff in the University of Ibadan. 
Evaluation of Musculoskeletal Fitness and its Relationship to Quality of Life of University Academic Staff in Nigeria

Table 3: Relationship between musculoskeletal fitness and participants' Quality of Life

\begin{tabular}{|c|c|c|c|c|c|c|}
\hline Variables & $\mathbf{N}$ & Mean & $\begin{array}{l}\text { Std. } \\
\text { Dev. }\end{array}$ & $\begin{array}{c}\text { PPMC } \\
(\mathbf{r})\end{array}$ & $\mathbf{P}$ & Remark \\
\hline Quality of Life & 36 & 21.83 & 2.26 & \multirow{3}{*}{.074} & \multirow{3}{*}{.770} & \multirow{3}{*}{ Not Sig. } \\
\hline & & & & & & \\
\hline Arm strength & 36 & 104.37 & 22.74 & & & \\
\hline Quality of Life & 36 & 21.83 & 2.26 & \multirow[b]{2}{*}{.029} & \multirow[b]{2}{*}{.909} & \multirow[t]{2}{*}{ Not Sig. } \\
\hline $\begin{array}{l}\text { Abdominal } \\
\text { Endurance }\end{array}$ & 36 & 32.00 & 6.27 & & & \\
\hline Quality of Life & 36 & 21.83 & 2.26 & \multirow[b]{2}{*}{.126} & \multirow[b]{2}{*}{.619} & Not Sig. \\
\hline Leg power & 36 & 45.94 & 4.94 & & & \\
\hline Quality of Life & 36 & 21.83 & 2.26 & \multirow[t]{2}{*}{.059} & \multirow[t]{2}{*}{.815} & Not Sig. \\
\hline Flexibility & 36 & 6.76 & 11.42 & & & \\
\hline
\end{tabular}

The results above show that there was no significant relationship between participants' musculoskeletal fitness and their physical health quality of life. The correlation value between quality of life and arm strength is $r=0.074$ while the crit value is 0.4683 . Likewise, the cal. $\mathrm{P}$ value of 0.770 is higher than 0.05 . Therefore, there is no significant relationship between arm strength and quality of life of the participants. The abdominal endurance shows a correlation value of $r=0.029$ which is lesser compared to the table value of 0.4683 and the cal. $\mathrm{P}$ value of 0.909 is higher than 0.05 level of significance. The leg power has a correlation value of $r=0.126$ which is lesser than the table value of 0.4683 and the cal. $\mathrm{P}$ value of 0.619 is higher than the significant level of 0.05 . Likewise, flexibility correlation value of $r=0.059$ is lesser than the table value of 0.4683 . Also, the cal. $\mathrm{P}$ of 0.815 is higher than 0.05 . Therefore, none of the four variables joined together is significantly correlated with the quality of life. The ruling is therefore that the null hypothesis is accepted. 
The result of the study on participants arm strength as presented in table 2 showed that there was significant difference between the participants' arm strength when compared with the standardized norm. For the participants, their arm strength was $60.97 \pm 21.3$ while the standard was $89.33 \pm 2.2$. This implies that the participants do not possess adequate arm strength required for their activities of daily living (ADLs). This may be due to the effect of age, because all the participants were within the age range of $40-69$ years, this corroborates Hurley (1995) that says muscular strength reaches its peak value at age 20-30 years then declines at approximately $45-50$ years. Likewise, Jette, Branch and Berlin (1990), reported that a reduction in hand function is a significant contribution to the impairment in performing basic activities of daily living. Giampaoli et al. (1999), also revealed that arm strength is an independent predictor of impaired function relating to capacity to perform activities of daily living.

The result as shown on table 2 indicated that there was a significant difference in the participants' abdominal endurance values of $18 \pm 666$ when compared to the standard norm. The obtained t-value of -10.48 was higher than the critical value of 2.0 at $\mathrm{df} 17$. The probability of 0.000 was lesser than 0.05 . The result implies that the participants do not possess adequate abdominal endurance required for their activities of daily living. Suni and Colleagues (1998) reported that trunk muscular endurance was a strong predictor of mobility and perceived health, respectively, in men and women. Salem et al., (2000) also reported that muscular endurance was directly associated with several functional outcomes.

The participants' leg power result presented on table 2 revealed that there was significant difference in the mean and standard deviation value of $28.94 \pm 4.65$ when compared with the expected norm of $32.83 \pm 1.51$. The obtained t-value of -3.65 was higher than the critical t-value of 2.0 at df 17 . The probability of 0.002 was lesser than 0.05 . This implied that the participants of this study do not possess adequate leg power. 
Evaluation of Musculoskeletal Fitness and its Relationship to Quality of Life of University Academic Staff in Nigeria

As reported under the result of the participants' flexibility shown on table 2 , the mean value of $1.26 \pm 10.25$ was lower than the standard norm values of $21.3 \pm 1.28$ which shows that there was significant difference between the flexibility of the participants with the standardized norm $($ Crit- $t=2.0$, Cal.t $=-7.86$ and $\mathrm{df}=17, \mathrm{P}<0.05)$. This implied that the participants do not possess adequate flexibility required for their activities of daily living.

The correlational result between musculoskeletal fitness and physical health quality of life of academic staff in University of Ibadan presented on table 3 showed the following results:

The Pearson Product Moment Correlation (PPMC) value of 0.074 that was obtained when arm strength was compared with physical health quality of life of participants, it shows no significant relationship. Likewise, the cal. $\mathrm{p}$ of 0.770 is higher than 0.05 level of significance, therefore the null hypothesis was not rejected. However, this result just attempt to determine the reason and not the effect of the relationship, neither does it shows that there is no relationship at all, but the value of $r=0.074$ is very low compared with 0.4683 . In addition, when these values were transformed on the WHOQoL (2012) domains, there is an indication that where there is low value of arm strength $(39.7 \mathrm{~kg})$ the quality of life rating (17) is also low and where the arm strength has higher mean value $(65 \mathrm{~kg})$ the quality of life also has high rate value (25). This is in line with the findings of Warburton et al (2001), that high levels of muscular strength are to be accompanied with a greater capacity to perform basic activities of daily living.

The abdominal endurance correlational value of 0.029 that was obtained when compared with physical health quality of life of participants shows that no significant relationship. The cal. $p$ of 0.909 is high, since the probability is $>0.05$. However, this result attempted to see if abdominal endurance is a factor to physical health quality of life of the participants. Therefore, the value of $r=$ 0.029 is very low compared with 0.4683 . In addition, the transformed score indicated that where there is low value of abdominal endurance (15) there is low quality of life rating (20) A Journal of the Department of Health, Physical Education and Recreation 
and where the abdominal endurance is high (21) the quality of life also has high rate value (26). This is in alignment with Suni and Colleagues (1998) report that trunk muscular endurance is a strong predictor of mobility and perceived health. Salem et al., (2000) also reported that muscular endurance is directly associated with several functional outcomes.

The findings of this study revealed that there is no significant relationship between the participants' leg power correlational value and their physical health quality of life as presented on table 3. Which shows correlation $r=0.126$ with calculated $\mathrm{p}$ of 0.619 . This result does not indicate effect relationship between participants' leg power and quality of life, neither is there an indication that there is no relationship at all, but with the value of $r=0.126$ which is very low compared with 0.4683 indicated that leg power is a factor to the physical health quality of life of the participants. Since on the WHOQoL (2012) domain table where there is low value of leg power $(23 \mathrm{~cm})$ there is low quality of life rating (17) but when the leg power is high $(32 \mathrm{~cm})$, the quality of life has high rate value $(26)$, this result corroborates the findings of Bassey et al., (1992) that loses in muscular power is associated with a decrease in functional ability.

The correlational value of 0.059 was obtained when compared participants' flexibility with their physical health quality of life. This results show that there is no significant relationship with cal. $p$ of 0.815 and $r$ value of 0.059 .

Furthermore, the domain table reflected that where there is low value of flexibility $(-7 \mathrm{~cm})$ there is low quality of life rating (17) and when the flexibility value is high $(9.2 \mathrm{~cm})$ the quality of life has high rating value (22). Warburton, Gledhill and Quinney (2001), reported that the relationship between flexibility and health status are specifically related to the impact of ageing on flexibility associated changes in functional status.

Worthy of note is that the participants poor flexibility (1.34 $\pm 10.20)$ may be attributed to their age, sex and body fat. According to Hockey (1996), these three are among the factors that affects flexibility. The participants' age range in this study is 
Evaluation of Musculoskeletal Fitness and its Relationship to Quality of Life of University Academic Staff in Nigeria

between 40-69years, while majority of the participants' BMI is above the normal baseline $(18.5-24.9)$ in the norm table classification (National Heart, Lung and Blood Institute, 1998). Likewise females have been reported to be more flexible than males.

\section{Conclusion}

The following conclusions and interpretations were made based on the findings of this study:

The University academic staff that took part in this study does not possesses adequate arm strength, abdominal endurance, leg power and have poor flexibility. Though, they rated themselves to possess average physical health quality of life. This claim could not be confirmed nor ascertained by their low qualities on the tested variables. This study therefore recommend regular periodic health examination of lecturers in order to be sure that they are fit for their job and prevent untimely death. This set of people needs to be encouraged to take active part in regular exercise programme and physical recreational activities as they claimed they are too busy to have time for such activities.

\section{References}

Canadian Society for Exercise Physiology 1996. Canadian Physical Activity, Fitness and Lifestyle Appraisal Manual. Ottawa, ON: Canadian Society for Exercise Physiology.

Ensrud, K.E., Nevitt, M.C., Yunis, C., Cauley, J.A., Seeley, D.G., Fox, K.M.and Cummings, S.R. 1994. Correlates of impaired function in older women. J. Am. Geriatr. Soc. 42: 481-489.

Erick, P. And Smith, D. 2013. Musculoskeletal disorder risk factors in teaching profession: a critical review $\mathrm{OA}$ Musculoskeletal Medicine. Dec. 01:1(3): 29.

Escalante, A., Lichtenstein, M.J., Dhanda, R., Cornell, J.E. and Hazuda, H.P. 1999. Determinants of hip and knee flexion range: Results from the San Antonio Longitudinal Study of Aging. Arthritis Care Res. 12: 8-18. 
Michael, G. \& Oladipo, I.O. (Ph.D)

Giampaoli, S., Ferrucci, L., Cecchi, F., Lo Noce, C., Poce, A., Dima, F., Santaquilani, A., Vescio, M.F. and Menotti, a. 1999. Hand-grip Strength predicts incident disability in non-disabled older men. Age Ageing 28: 283-288.

Hennessy, C.H., Moriarty, D.G., Zack, M.M., Scherr, P.A. and Brackbill, R. 1994. Measuring health-related quality of life for public health surveillance. Public Health Rep. 109:665-672.

Hockey, R.V. 1996. Physical Fitness: The Pathway to Healthy Living. $8^{\text {th }}$ ed. USA. McGraw-Hill.

Hurley, V.F. 1995. Age, gender and muscular strength. $J$. Gerontol. A Biol. Sci Med. Sci. 50 (Spec No): 41-44.

Jette, A.M., Branch, L.G. and Berlin, J. 1990. Musculoskeletal impairments and physical disablement among the aged. $J$. Gerontol. 45: M203-M208.

Kell, R.T., Bell, G. And Quinney, A. 2001. Musculoskeletal fitness, Health Outcomes and Quality of Life. Sports Med 312: 863-873.

National Heart, Lung and Blood Institute, 1998. Clinical guidelines on the identification, evaluation and treatment of overweight and obesity in adult; the evidence report Bethesda, MD: National Institute of Health.

Payne, N., Gledhill, N., Katzarmzyk, P., Jamnik, V. And Ferguson, S. 2000. Health implications of musculoskeletal fitness. Can. J. Appl. Physiol. 25:114-126.

Salem, G.J., Wang, M.Y., Young, J.T., Marion, M. and Greendale, G.A. 2000. Knee strength and lower and higher-intensity functional performance in older adults. Med. Sci. Sports Exerc. 32: 1679-1684

Suni, J.H., Oja, P., Miilunpalo, S.I., Pasanen, M.E., Vuori, I.M. and Bos, K. 1998. Health-related fitness test battery for adults: Associations with perceived health, mobility and back function and symptoms. Arch. Phys. Med. Rehabil. 79: 559-569. 
Evaluation of Musculoskeletal Fitness and its Relationship to Quality of Life of University Academic Staff in Nigeria

Warburton, D.E.R., Gledhill, N. And Quinney, A. 2001. Musculoskeletal fitness and health. Can. J. Appl. Physiol. 26: 217-237.

World Health Organization 2005. The World health Organization Quality of Life assessment (WHOQOL): position paper from the World Health Organization. SocSci Med 2005; 41(10):1403-1409. 